\title{
Influence of geometrical parameters arrangement on solidification process of ice-on-coil storage system
}

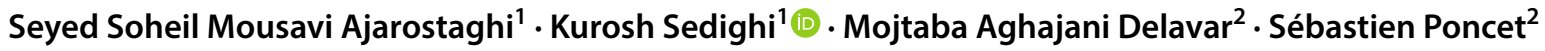

Received: 13 September 2019 / Accepted: 13 December 2019 / Published online: 18 December 2019

(c) Springer Nature Switzerland AG 2019

\begin{abstract}
Ice storage systems are one kind of thermal (cold) storage systems which by shifting the usage from high to low load hours (midnight or morning), balances the period of consumption. In the present investigation, the solidification process is studied in an ice storage system. The considered system is the ice-on-coil type which the ice is formed around the cold wall of coils. The considered ice storage system is a two dimensional square shell and different numbers of heat transfer fluid tubes. Two-dimensional transient numerical simulations are performed by ANSYS FLUENT 18.2. The influences of the tube diameter and number and the arrangement of the tubes on the solidification process are evaluated. Three different tube diameters, including 12, 18, and $24 \mathrm{~mm}$ are considered. Also, two different arrangements of tubes, including in-line and triangular arrangements are studied. Results indicate that as the diameter of the tubes decreases or the number of tubes increases at constant mass flowrate of the heat transfer fluid, ice formation speeds up. Also, the triangular arrangement as a staggered arrangement results in faster ice formation in comparison with the in-line arrangement. As a result, an accepted correlation for liquid fraction is presented between the numerical results and predicted values as a function of tube diameter and melting time.
\end{abstract}

Keywords Ice-on-coil · Cold storage system · Solidification · Thermal energy system (TES) - Numerical simulation · Enthalpy-porosity method

\section{List of symbols}

A Heat transfer area $\left(\mathrm{mm}^{2}\right)$

$C_{\text {mush }}$ Mushy zone constant $\left(\mathrm{kg} / \mathrm{m}^{3} \mathrm{~s}\right)$

$C_{p} \quad$ Specific heat $(\mathrm{J} / \mathrm{kg} \mathrm{K})$

$D \quad$ Tube outer diameter $(\mathrm{mm})$

$\vec{g} \quad$ Gravity $\left(\mathrm{m} / \mathrm{s}^{2}\right)$

$H \quad$ Serpentine tube row distance $(\mathrm{mm})$

$h \quad$ Specific enthalpy $(\mathrm{J} / \mathrm{kg})$

$h_{\text {sf }} \quad$ Latent heat of fusion $(\mathrm{J} / \mathrm{kg})$

$k \quad$ Thermal conductivity (W/m k)

$L \quad$ Tube length ( $\mathrm{mm}$ )

$P \quad$ Serpentine tube pitch $(\mathrm{mm})$

$\vec{s} \quad$ Source term $\left(\mathrm{N} / \mathrm{m}^{3}\right)$

$T \quad$ Temperature $(\mathrm{K})$

$\vec{V} \quad$ Velocity vector $(\mathrm{m} / \mathrm{s})$
Greek symbols

$\beta \quad$ Expansion coefficient (1/K)

$\lambda \quad$ Liquid fraction

$\mu \quad$ Dynamic viscosity (Pa s)

$\rho \quad$ Density $\left(\mathrm{kg} / \mathrm{m}^{3}\right)$

\section{Subscripts}

ref Reference

0 Reference

sens Sensible

lat Latent

tot Total

$s \quad$ Solid

liq Liquid

Kurosh Sedighi, ksedighi@nit.ac.ir; Seyed Soheil Mousavi Ajarostaghi, s.s.mousavi@stu.nit.ac.ir; Mojtaba Aghajani Delavar, m.a.delavar@nit.ac.ir; Sébastien Poncet, sebastien.poncet@usherbrooke.ca| ${ }^{1}$ Mechanical Engineering Department, Babol Noshirvani University of Technology, Babol 47148-71167, Iran. ${ }^{2}$ Mechanical Engineering Department, Université de Sherbrooke, Sherbrooke, QC J1K 2R1, Canada. 


\section{Introduction}

The enormous consumption of energy, especially for electrical demand from polluting energy sources, is expected to increase by $48 \%$ till 2040 [1]. There is then a growing interest in sustainable energy sources for energy demand growth of power industries [2]. Thermal energy storage is an efficient method to shift the peak load hours from day to night which balances the energy consumption in $24 \mathrm{~h}$ a day [3]. On the other hand, in cold storage systems like ice-on-coil type, the load is shifted from the afternoon (peak time) to midnight (as off-peak time). Utilizing cold storage systems leads to decrease in size of refrigeration systems equipment and finally decline in energy cost [4]. Thermal energy storage (TES) systems has vast applications in different industries like HVAC and can easily reduce the energy costs and play significant role in reducing carbon emissions [5]. In the case of intermittent energy sources such as solar systems, TES systems can be efficient to absorb and release energy during the daylight and the night (heating purposes), respectively $[6,7]$.

Cold storage technologies consist of a storage domain which works between two mechanisms of melting (discharge) and solidification (charge) of phase change material (like water/ice). Ice-on-coil cold storage systems are divided to two types, including internal melt and external melt which the melting process starts from inside and outside, respectively [8]. However, the charging process (solidification) is the same for these two types of cold storage systems. Cold heat transfer fluid, such as ethylene glycol, flows in the coil, and then ice is produced around the coil tube. The difference between these two types of ice storage systems is the melting process.

In recent years, numerous investigations (experimental or numerical) have been carried out to determine the performance of the ice storage system in HVAC systems. Rahdar et al. [7] investigated two plans to decrease the electricity usage of HVAC systems during high load time using a comparative exergetic, economic and environmental analysis. The studied HVAC system consisted of a PCM storage and an ice storage. According to the obtained results, electricity consumption for considered new HVAC system was about 4.9-7.5\% lower than conventional HVAC systems. Also, $\mathrm{CO}_{2}$ emission was reduced significantly. Kang et al. [8] reported that utilizing ice storage systems leads to lower costs and power consumption in peak periods. There are also some investigations to study the charge or discharge processes (melting and solidification) in ice storage systems. In order to improve the thermal performance of ice-on-coil cold storage systems, Jannesari and Abdollahi [9] utilized thin ring and fins around the straight tubes. The results showed that utilizing rings and fins lead to more solidification rate more than $34 \%$ and $21 \%$, respectively. Shih and Chou [10] investigated the freezing process in a storage. The influences of number of tubes and the arrangements were studied numerically.

Yang et al. [11] studied the effect of inlet condition of the fluid on solidification rate in an cold storage system. According to the obtained results, low inlet temperature leads to higher solidification rate. Erek and Ezan [12] studied the influences of inlet temperature and mass flowrate of ethylene glycol as heat transfer fluid on solidification process in an ice storage system. The refrigerant temperature had a predominant influence on the ice formation, as compared with the one of the mass flowrate. Ezan et al. [13] performed an energy and exergy analysis for an ice storage system. The influences of inlet temperature and flowrate of heat transfer fluid (refrigerant) on solidification process were studied. The results showed that as the inlet temperature declines, the charging time decreases $50 \%$. Sang et al. [14] studied an ice-on-coil cold storage system with vertical position. The charging and discharging processes via a proposed new efficient numerical approach based on enthalpy method were analyzed. The proposed method was validated in both processes of solidification and melting (charge and discharge) with the experimental results.

Mousavi Ajarostaghi et al. [15] numerically investigated the ice melting in an internal melt ice-on-coil ice storage system. The effect of operational (mass flowrate and temperature) and geometrical (coil pitch, diameter, and height) parameters on the discharge process were investigated. Results revealed that increasing the inlet temperature or mass flowrate leads to enhanced melting rate. Additionally, the coil diameter has a predominant effect on the melting time. Pakzad et al. [16] performed a three-dimensional numerical study to evaluate the water freezing in an ice-on- coil cold storage system which serpentine tube is utilized instead of straight tube. The effects of geometrical parameters on ice formation were studied. According to the obtained results, as the distance between tube rows rises, solidification rate increases. Also, higher tube diameter leads to lower solidification rate. Afsharpanah et al. [17] studied the water freezing in an ice-oncoil ice storage system with a double helical coil. Based on their results, by increasing the pitch size (50\%) and distance between the coils (33.34\%), solidification rate rises by $22.81 \%$ and $13.99 \%$, respectively.

Zheng et al. [18] modeled the melting and solidification processes in an internal melt ice-on-coil cold storage system using Simulink. Obtained results showed as the coil diameter increases, the thermal efficiency of the considered system rises. Xie and Yuan $[19,20]$ reported that the properties of the thin layer ring have significant effect on the water freezing. Ismail et al. [21] performed 
two-dimensional simulations of the ice formation (solidification) around a bent tube. Results indicated that as the wall temperature increases, the ice formation rate decreases. Also, higher initial temperature of liquid PCM leads to higher solidified mass.

Sheikholeslami and Rokni [22] investigated the melting process of $\mathrm{CuO}$-water nanofluid by control volume finite element method. The effects of melting parameter, $\mathrm{CuO}-$ water volume fraction, Hartmann and Rayleigh numbers were studied. Results showed that increasing the Rayleigh and melting parameter could lead to higher temperature gradient. In another work, Sheikholeslami [23] studied the solidification process of $\mathrm{CuO}$ nanoparticles with various shapes into the base fluid (water). Galerkin finite element method considering adaptive mesh was utilized. Results showed that utilizing nanoparticles accelerates the solidification process. Also, Sheikholeslami [24, 25] presented another work which investigated the solidification process in a latent heat thermal energy storage systems which CuO-water nanofluid was considered as PCM. Effects of inner cylinder's shape, diameter of nanoparticles and nanofluid volume fraction on solidification process were demonstrated. Their study obtained an optimum for dimension of the inner heat transfer fluid tube. Following from previous studies, Sheikholeslami [26] analyzed the solidification process of Nano enhanced phase change material in existence of radiative heat transfer. Nanofluid water/CuO was used as PCM. Finite element method with adaptive mesh was employed to simulate this transient problem. Influences of fin length, size of nanoparticle, nanofluid volume fraction, radiation parameter on solidification process were studied. Results indicated that solidification rate enhances by dispersing $\mathrm{CuO}$ nanoparticles into water.

Gawande and Ingole [27] presented a comparative study of heat storage and transfer systems for solar cooking. For the development of efficient solar cooker, heat storage is essential and in turn the heat transfer system also becomes necessary. In this paper, the key aspects like, methodology to develop the heat storage system, requirements and properties of heat storage materials, need of insulations and their types were addressed. In this system, PCM to be used for which, Paraffin Wax, Myo-inositol, $\mathrm{HDPE}, \mathrm{NaOH}-\mathrm{H}_{2} \mathrm{O}$ and $\mathrm{KNO}_{3}-\mathrm{NaNO}_{2}-\mathrm{NaNO}_{2}$ materials looked more promising. Pradhan and Ramaswamy [28] reported the encapsulation of paraffin wax with the cross-linked poly (styrene-divinylbenzene-acrylic acid) shell via suspension polymerization. The thermal charging-discharging rate of the considered encapsulated phase change materials (EPCM) was studied using a facile water bath technique. The optimized EPCM showed about 1.7 times faster-charging and 3.5 times faster discharging rate compared to the reference PCM (without encapsulation). The latent heat for the EPCM was found to be about 3.3 times higher than the reference PCM. Recently, there have been many other interesting studies on the solidification process of PCM (or water as PCM) with the addition of nanoparticles [29-32].

In this survey, the solidification process in an ice storage system (ice-on-coil type) is evaluated by performing $2 \mathrm{D}$ numerical simulation. The considered computational domain is a two dimensional square shell and different numbers of heat transfer fluid tubes. Two-dimensional transient numerical simulations are performed using ANSYS FLUENT 18.2. The influences of the tube diameter and number and the arrangement of the tubes on the solidification process are evaluated. Three different diameters of tubes, including 12, 18, and $24 \mathrm{~mm}$ are considered. Also, two different arrangements of tubes, including in-line and triangular arrangements are studied. To the best of the authors' knowledge, it has not been considered so far in the literature. Actually, in the former works related to the solidification process of water (as PCM), the specific thermophysical properties of water and ice have not been considered separately. Here, three different validations are presented to show the accuracy and the enhanced performance of the model. Also, in the works published so far on ice storage systems, the combined influence of the tube dimension and their arrangement on the solidification process have not been studied, which represents certainly the major novelty of the present paper.

\section{Numerical modeling}

\subsection{Governing equations}

To consider the natural convection and buoyancy affect, the Boussinesq approximation is utilized [33]:

$\rho=\rho_{0}\left(1-\beta\left(\left(T-T_{0}\right)\right)\right)$

The continuity conservation [34]:

$\nabla \cdot \vec{V}=0$

The momentum conservation [34]:

$\frac{\partial V}{\partial t}+\vec{V} \cdot \nabla \vec{V}=\frac{1}{\rho}\left(-\nabla P+\mu \nabla^{2} \vec{V}+\rho g \beta\left(T-T_{\text {ref }}\right)\right)+\vec{S}$

And the conservation equation for energy [34]:

$\frac{\partial h_{\text {sens }}}{\partial t}+\frac{\partial h_{\text {lat }}}{\partial t}+\nabla \cdot\left(\vec{V} h_{\text {sens }}\right)=\nabla \cdot\left(\frac{k}{\rho c_{p}} \nabla h_{\text {sens }}\right)$

The total enthalpy can be obtained by $[15,35]$ : 
$h_{\text {tot }}=h_{\text {sens }}+h_{\text {lat }}$

where

$h_{\text {sens }}=h_{\text {ref }}+\int_{T_{\text {ref }}}^{T} c_{p} d T=h_{\text {ref }}+c_{p} \int_{T_{\text {ref }}}^{T} d T$

$h_{\text {lat }}=\lambda \cdot h_{\text {sf }}$

$h_{\text {lat }}$ is the latent heat and $h_{\text {sf }}$ denotes the latent heat for the solid and liquid phases. $h_{\text {lat }}$ changes within the range between zero (solid phase) and $h_{s f}$ (liquid phases). $\lambda$ is liquid fraction. The sensible heat is defined as follows:

$h_{\text {sens }}=h_{\text {tot }}-h_{\text {lat }}$

The liquid fraction is defined as follows [36]:

$\lambda=\left\{\begin{array}{ll}\frac{h_{\text {lat }}}{h_{\text {sf }}}=0 & \text { if } T \leq T_{s} \\ \frac{h_{\text {lat }}}{h_{s f}}=1 & \text { if } T \geq T_{\text {liq }} \\ \frac{h_{\text {lat }}=\frac{T-T_{s}}{h_{\text {sf }}}}{T_{\text {liq }}-T_{s}} & \text { if } T_{s}<T<T_{\text {liq }}\end{array}\right\}$

The term $\mathrm{S}$ in momentum conservation equation is the Darcy's law damping source term, which is defined as follows:

$\vec{S}=-\frac{(1-\lambda)^{2}}{\lambda^{3}} C_{\text {mush }} \vec{V}$

where $C_{\text {mush }}$ is considered to $10^{5} \mathrm{~kg} /\left(\mathrm{m}^{3} \mathrm{~s}\right)$ here as mushy zone constant [33].

\subsection{Numerical method}

The numerical solver is based on the finite volume method. The governing equations written in a Cartesian frame are solved in $2 \mathrm{D}$ and under their unsteady formulation. ANSYS Fluent 18.2 is used to perform the numerical simulations. The enthalpy-porosity method is considered to simulate the phase change process. The SIMPLE algorithm is used to overcome the pressure-velocity coupling. The spatial discretization for both momentum and energy equations is done through the QUICK scheme, where a first-order implicit scheme is chosen for the temporal discretization. The least square cell-based is used for the gradient spatial discretization. The solution is considered as converged when the residuals for continuity, velocity, and energy reach $10^{-3}, 10^{-3}$, and $10^{-6}$, respectively. The under-relaxation factors are fixed to $0.3,1,0.7$, and 0.9 for pressure, density, body forces and energy, momentum, and liquid fraction update, respectively.

\section{Results and discussion}

Here, two geometrical parameters including diameter of the tubes and the arrangement of the tubes on the thermal performance of the ice storage system with straight tubes are investigated numerically.

\subsection{Validation cases}

For the 2D validation of the ice solidification process, three different cases are modelled in 2D. For all models, the thermophysical properties of ice/water and ethylene glycol [9] are listed in Table 1, and are assumed to be constant.

\subsubsection{Water freezing in case one}

The first case concerns the modelling of water freezing in a cubic cavity of a height $L$. At the cold wall, $T_{c}=263 \mathrm{~K}$. Two vertical walls are temperature constant which $\mathrm{T}_{\mathrm{H}}-\mathrm{T}_{\mathrm{C}}=10 \mathrm{~K}$. All remaining walls are adiabatic. At the initial condition, $T_{0, \text { Fluid }}=278 \mathrm{~K}$. In the present case, an unstructured mesh grid composed of 144,400 tetrahedral cells ( $380 \times 380$ nodes) is considered with a time step fixed to $0.1 \mathrm{~s}$. Dimension of the cavity $L$ is $38 \mathrm{~mm}$ (see Fig. 1a). The present results are compared with the experimental ones obtained by Michalek and Kowalewski
Table 1 Thermophysical properties of ice/water and ethylene glycol [9]

\begin{tabular}{lll}
\hline Parameter & Symbol & Value \\
\hline Density of fluid $\left(\mathrm{kg} / \mathrm{m}^{3}\right)$ & $\rho_{\mathrm{f}}$ & 999.833 \\
Specific heat of the fluid $(\mathrm{J} / \mathrm{kg} \mathrm{K})$ & $\mathrm{C}_{\mathrm{l}}$ & 4180 \\
Specific heat of the solid $(\mathrm{J} / \mathrm{kg} \mathrm{K})$ & $\mathrm{C}_{\mathrm{S}}$ & 2217 \\
Thermal conductivity of liquid water $(\mathrm{W} / \mathrm{m} \mathrm{K})$ & $\mathrm{K}_{\mathrm{S}}$ & 1.918 \\
Thermal conductivity of ice $(\mathrm{W} / \mathrm{m} \mathrm{K})$ & $\mathrm{K}_{\mathrm{l}}$ & 0.578 \\
Viscosity of the fluid $(\mathrm{kg} / \mathrm{m} \mathrm{s})$ & $\mu_{\mathrm{f}}$ & 0.00162 \\
Latent heat of phase change $(\mathrm{J} / \mathrm{kg})$ & $\mathrm{L}$ & 334,000 \\
Melting temperature $(\mathrm{K})$ & $\mathrm{T}_{\mathrm{f}}$ & 273.15 \\
Thermal expansion coefficient $\left(\mathrm{K}^{-1}\right)$ & $\beta$ & $-6.733353 \times 10^{-5}$ \\
\hline
\end{tabular}


[37]. As shown in Fig. 1b, c, a fairly good agreement can be observed in terms of the distributions of both velocity and temperature.

\subsubsection{Water freezing in case two}

Two different 2D domains including one and two cylinders in a cavity are considered to model the ice formation. The obtained results of the present simulations are compared with the experimental ones of Sasaguchi et al. [38]. The geometries of the one and two cylinders in a cavity filled with water are shown in Fig. 2a. Here the geometrical parameter $d$ is $0.0254 \mathrm{~m}$. The initial temperature of the domain and the wall temperature of the cylinders are kept constant $4{ }^{\circ} \mathrm{C}$ and $-10{ }^{\circ} \mathrm{C}$, respectively. The time step is fixed to $0.1 \mathrm{~s}$. The considered grid is composed of 3131 and 3751 tetrahedral cells for the one and two cylinder cases, respectively.

The solid volume ratio, $A_{s} / A_{C}$, the ratio of the solidified area to the total cross-sectional area, is used to draw the validation curves. The validation curves with good agreement of both models from the present simulations in comparison with the experimental results are shown in Fig. 2b, c.

\subsubsection{Water freezing in case three}

In this section, ice formation around the multi tubes (four) in a cavity (full of water) is studied. The computational domain and boundary conditions are illustrated in Fig. 3a, b. The considered grid is composed of 3536 tetrahedral cells and is associated with a time step equal to $0.1 \mathrm{~s}$. The

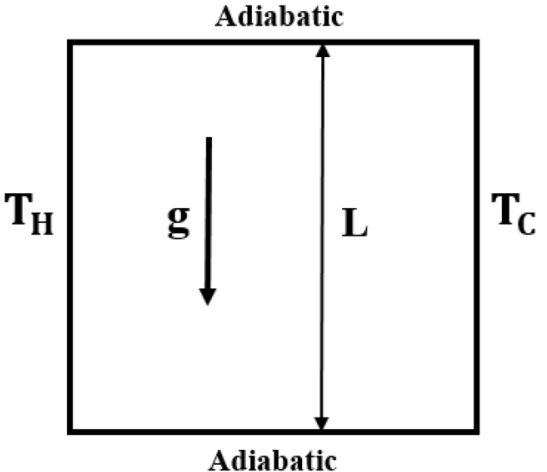

(a)

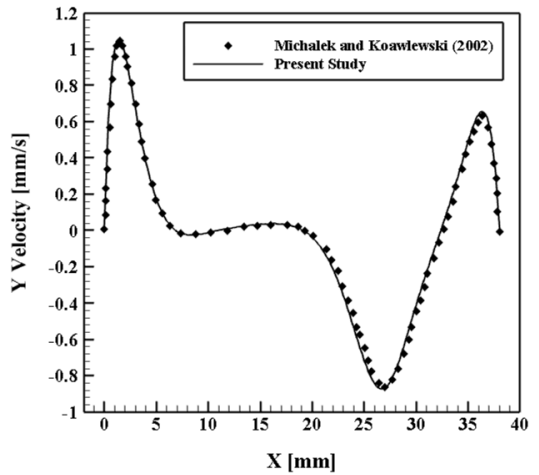

(b)

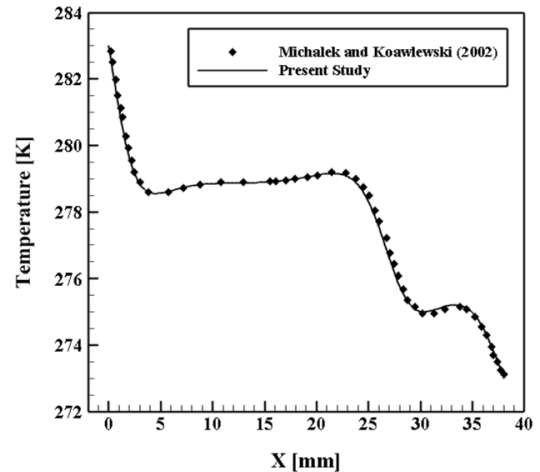

(c)

Fig. 1 a The 2D configuration to investigate the ice formation, b, c comparisons between the present simulations and the results of Michalek and Kowalewski [37]

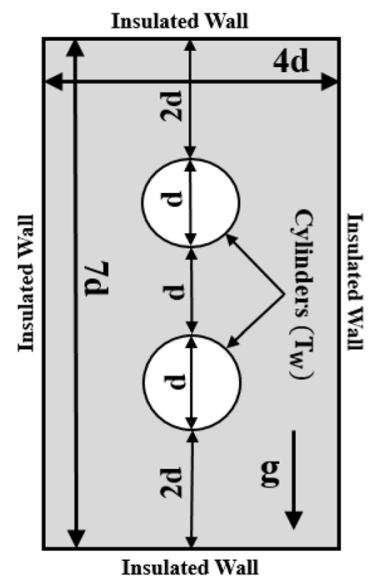

(a)

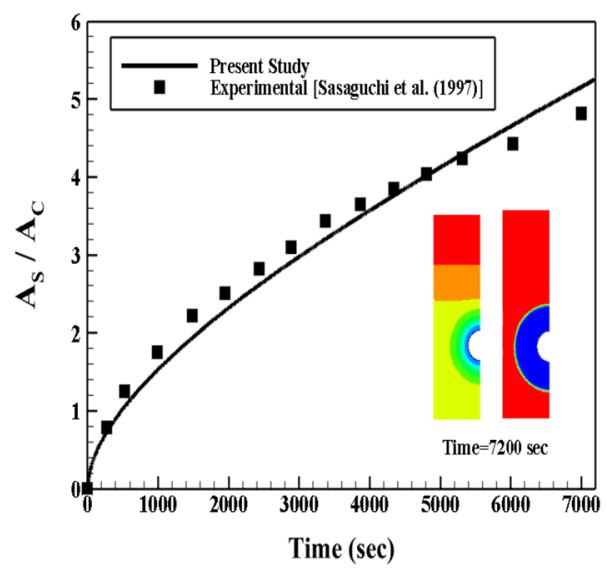

(b)

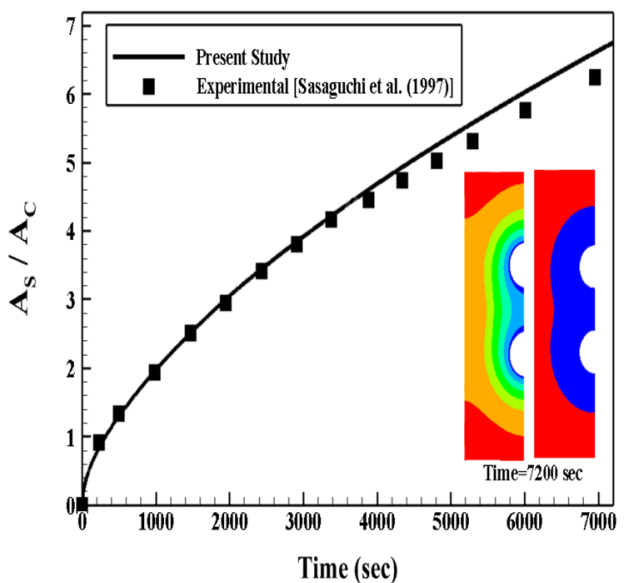

(c)
Fig. 2 a The geometries of the single and two vertically spaced cylinders in a rectangular cavity which is full of water at the solidification point; comparison between the present numerical results and the experimental results of Sasaguchi et al. [38] for $\mathbf{b}$ a single cylinder and $\mathbf{c}$ two vertical spaced cylinders 


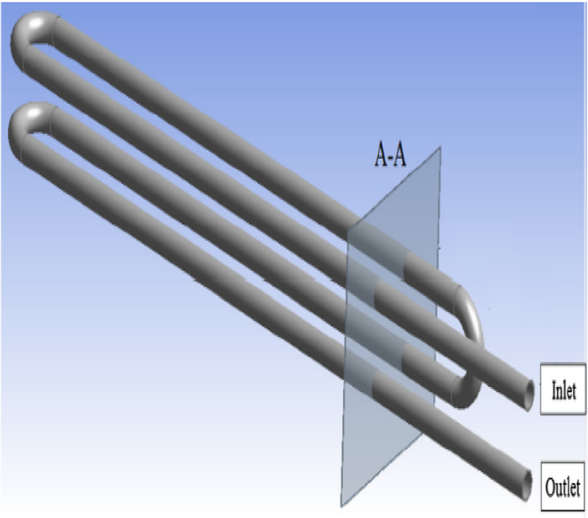

(a)

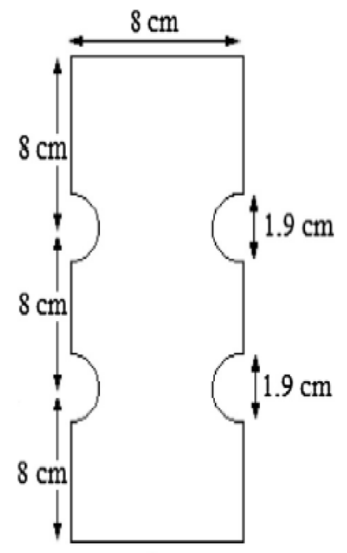

(b)

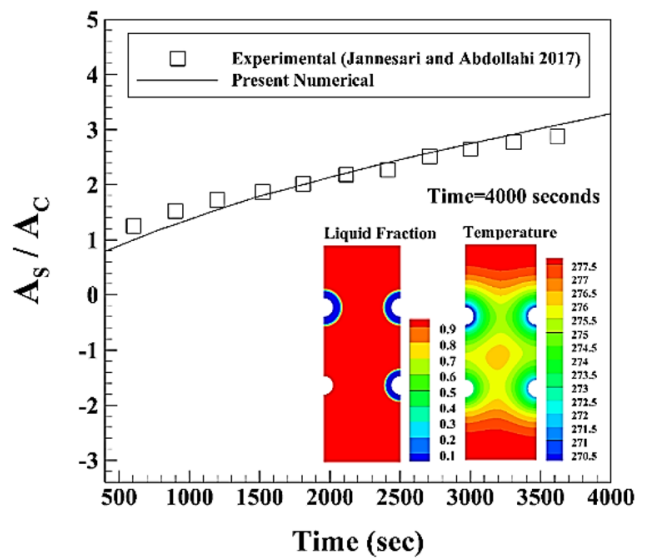

(c)

Fig. 3 a General view of the tubes in the cold storage tank; b computational domain with relevant geometrical dimensions; c comparison in terms of solid volume ratio, $A_{S} / A_{C}$, between the present numerical results and the experimental ones in Jannesari and Abdollahi [9]

experimental results of Jannesari and Abdollahi [9] are considered here for validation study. The temperature of tubes is set to $270.15,270.65,271.15$ and $273 \mathrm{~K}$, for first tube to fourth one, respectively. The time wise solid volume ratio, $A_{S} / A_{C}$, is used to draw the validation curve in the Fig. 3c. It can be seen that a fairly good agreement is achieved between the present study and the experimental results of Jannesari and Abdollahi [9].

\subsection{Grid independency study}

In order to study the grid independency of the solution, the case with $d=24 \mathrm{~mm}$ has been considered. 10 prismatic layers are imposed around the HTF walls with a first length of 0.05 and a growth ratio of 1.2. Three different grids, including 1689,4910 , and 7360 cells are generated for this case. The results of the mesh independency study are illustrated in Fig. 4. It can be seen that the difference between the second and third grids is negligible, the blue and red curves being besides undistinguishable. So, to save computational time, the second grid with 4910 cells will be used for all the upcoming. This grid is displayed in Fig. 5.

\subsection{Computational domain}

The two dimensional computational domain is a square of length $L$. The diameter of the heat transfer fluid (HTF) tubes is denoted $d$. The placement of the tubes in the 2D square storage is shown in Fig. 6a. Because of the symmetry condition of the solidification process and also the arrangement of the tubes, only half of the computational domain is simulated (see Fig. 6b). The temperature at the tube walls is considered as constant. The other walls of the

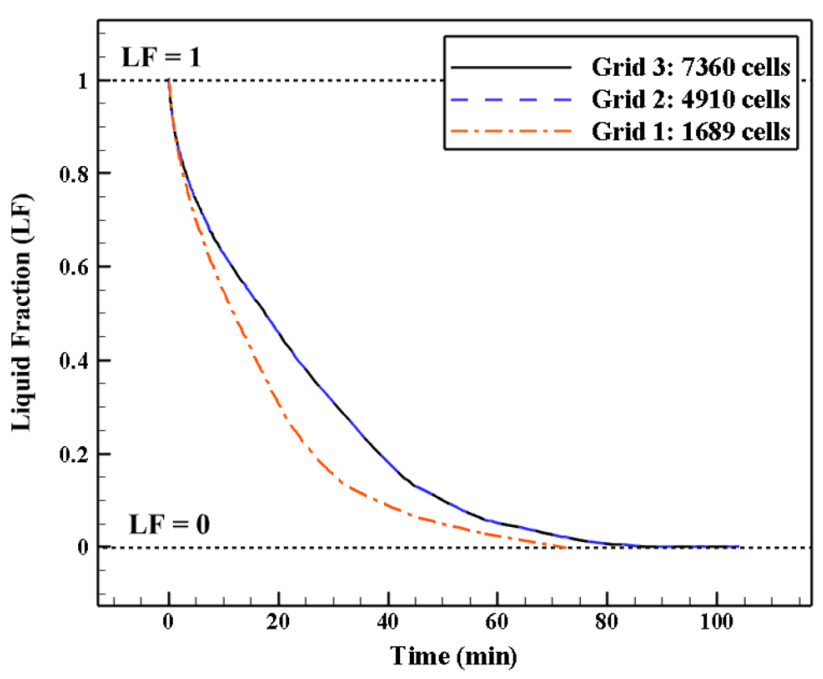

Fig. 4 Results of the grid independency study in terms of temporal evolution of the liquid fraction for $d=24 \mathrm{~mm}$

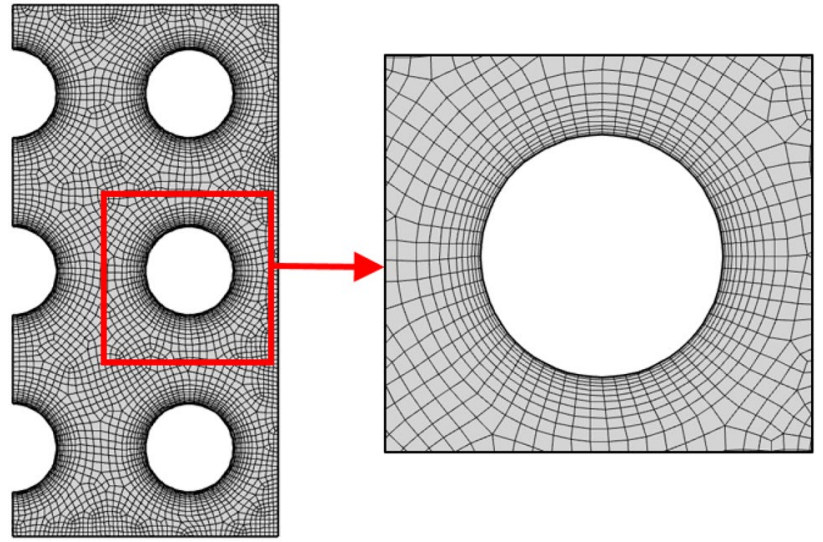

Fig. 5 Generated grid with 4910 cells for $d=24 \mathrm{~mm}$ 


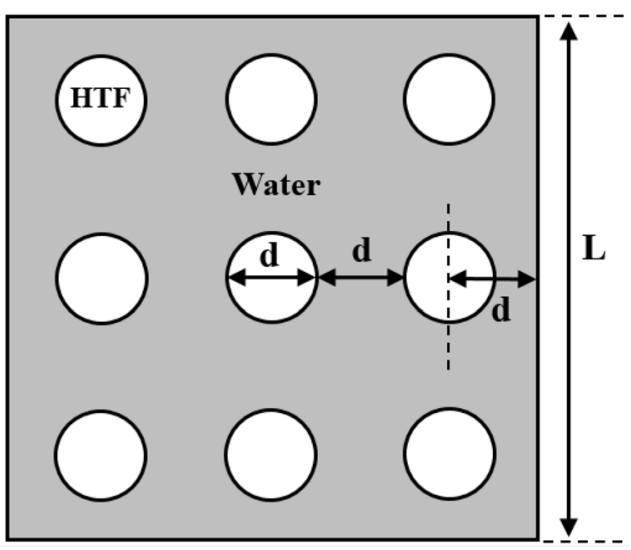

(a)

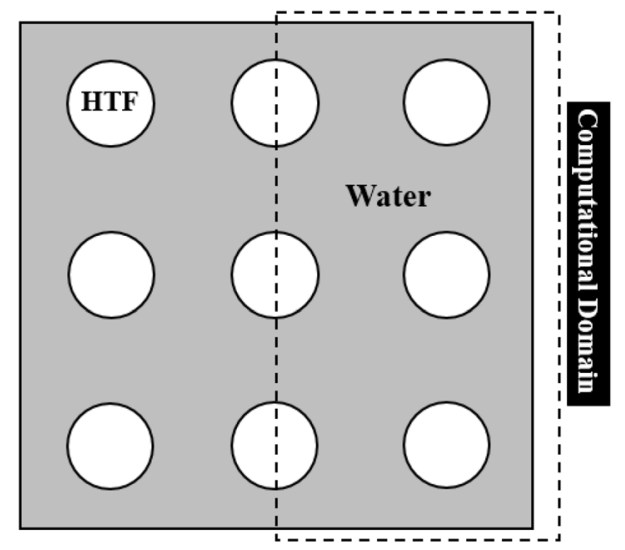

(b)

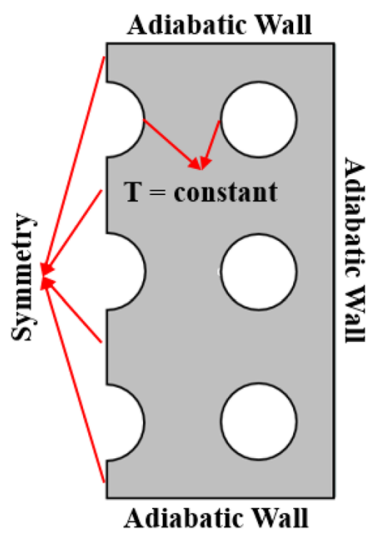

Fig. 6 a Studied geometry with the geometrical parameters, and $\mathbf{b}$ the computational domain

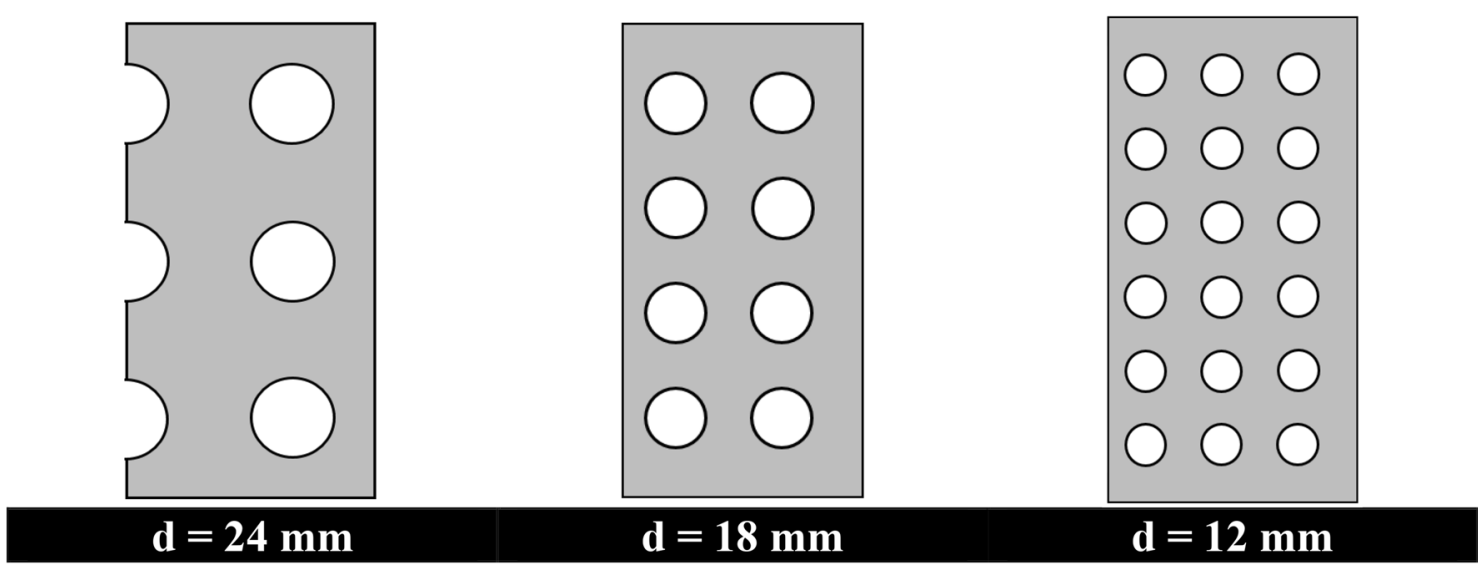

Fig. 7 Schematic view of the ice storage with different tube diameters

computational domain are adiabatic. A time step of $0.1 \mathrm{~s}$ with an unstructured mesh grid composed of 3310 cells for the case with $\mathrm{d}=24 \mathrm{~mm}$ are used.

\subsection{The effect of the diameter of the tube $\left(d_{1}\right)$}

In this section, the effect of the diameter of the tubes is investigated numerically. Three different diameter of the tube including 12, 18 and $24 \mathrm{~mm}$ are considered here. It should be noted that the mass flowrate of the heat transfer fluid in all models is kept constant. Accordingly, by increasing the diameter of the tubes, the number of the tubes decreases. In all models with different diameter and also different number of tubes, the tubes are placed in the shell in a line position. The schematics of the ice storage with different diameter of the tubes are illustrated in Fig. 7.

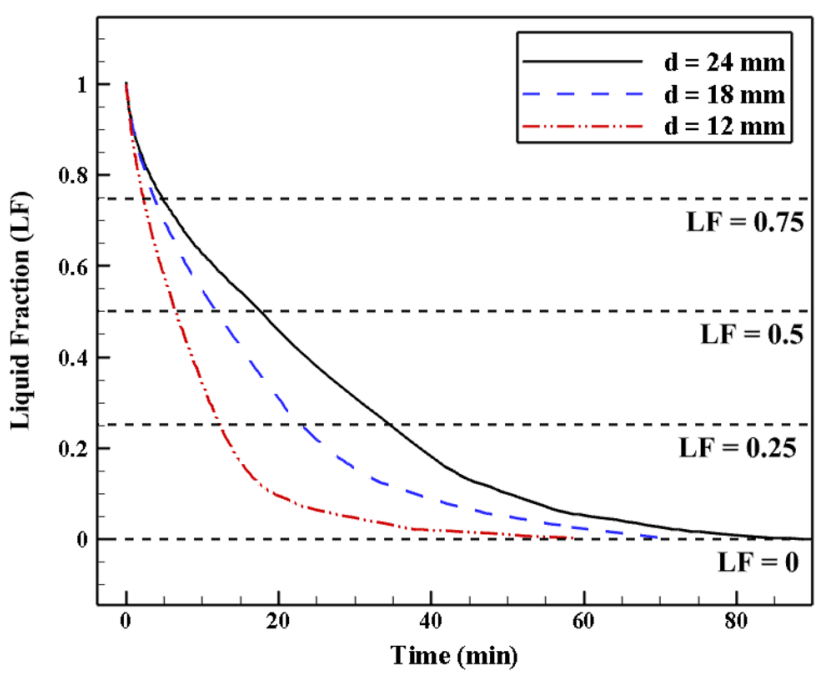

Fig. 8 Temporal evolution of the liquid fraction (LF) for different tube diameters 
Fig. 9 Contours of liquid fraction (LF) for three different diameters of tubes $\left(d_{1}\right)$ and four different times

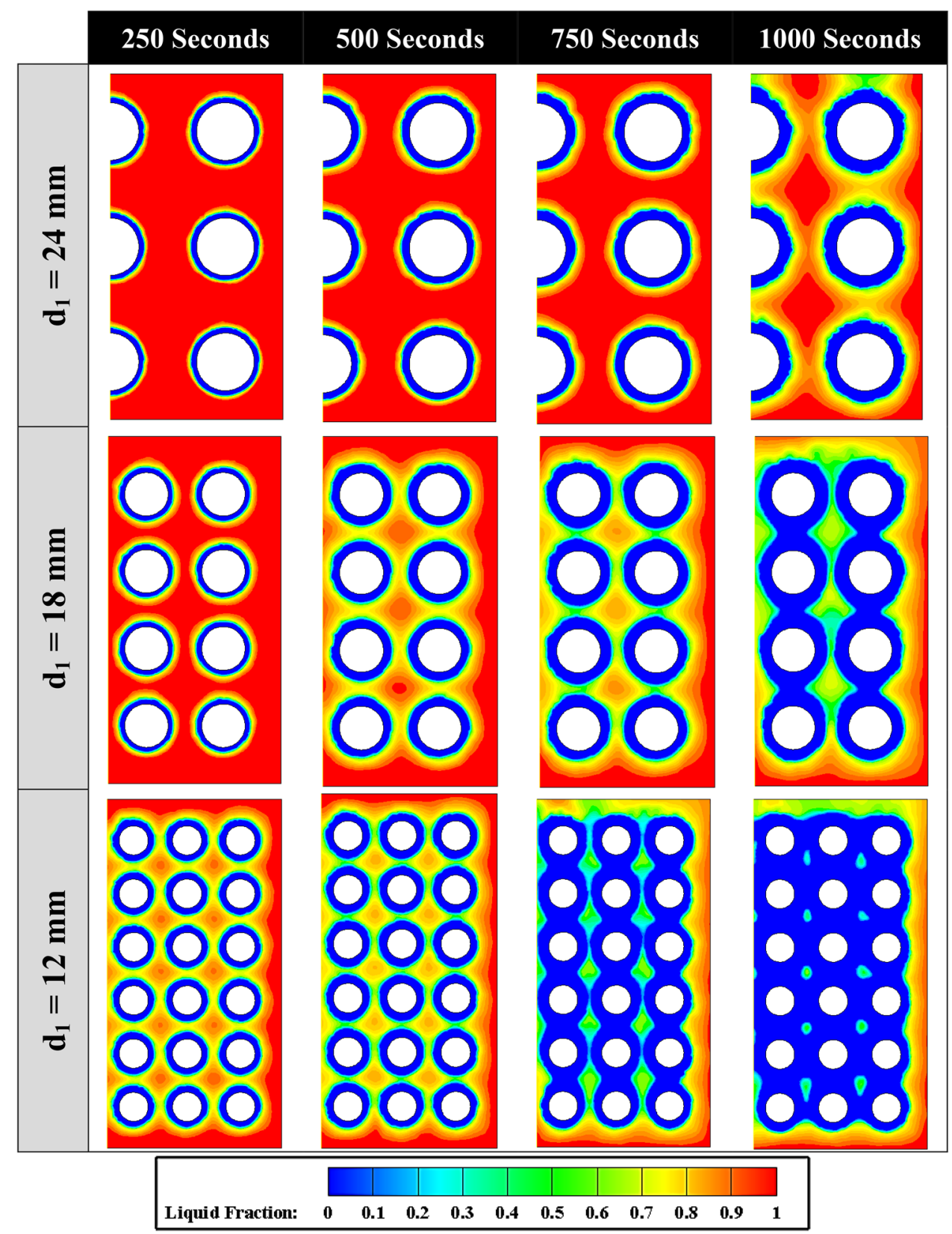

According to Fig. 9, it can be seen that by declining the diameter of the tubes, because of keeping constant the mass flowrate of heat transfer fluid (HTF), the number of tubes rises. So, more area is covered by the tubes which leads to more produced ice. These results are shown clearly in Fig. 9. For instance, at time $=1000 \mathrm{~s}$, more ice is formed around the tubes in the model with $d_{1}=12.7 \mathrm{~mm}$ in comparison with the other models. 
Fig. 10 The studied configurations: a triangular arrangement, and $\mathbf{b}$ in-line arrangement

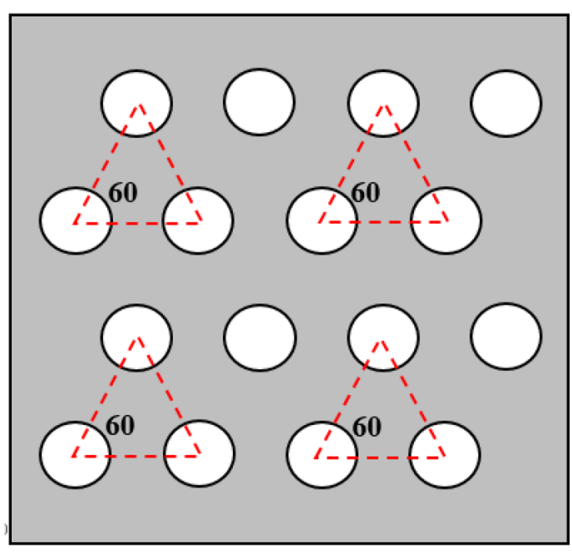

(a)

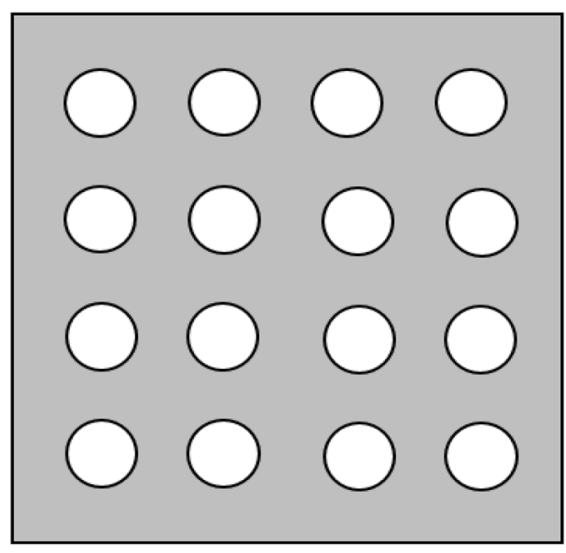

(b)

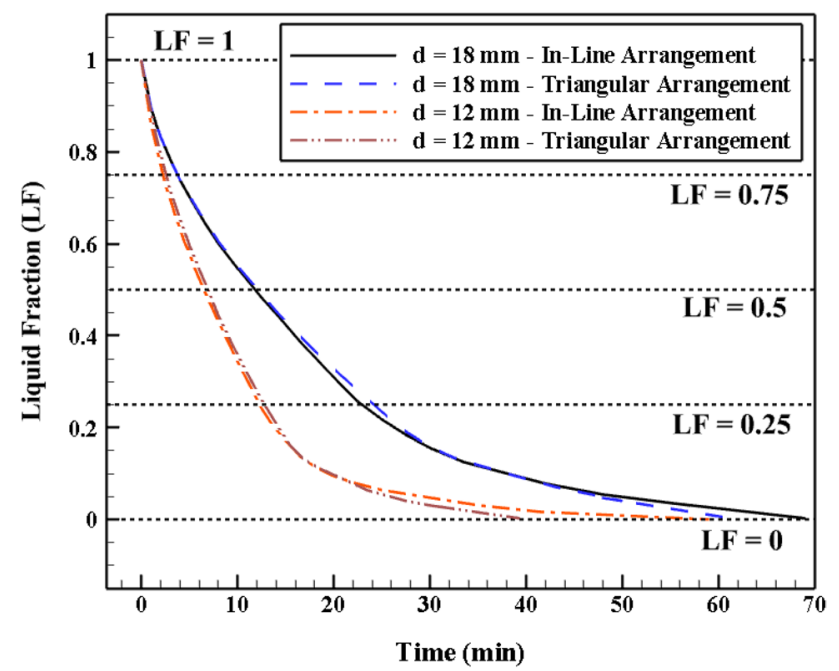

Fig. 11 Temporal evolution of the liquid fraction (LF) for two different diameters and two arrangements of the HTF tubes

\subsection{The effect of the arrangements of the tubes}

In this section, the effect of the arrangement of the tubes is evaluated numerically. Two different arrangement of the tubes including in-line and triangular are considered here. It should be noted that the mass flowrate of the heat transfer fluid in all models is kept constant. The schematics of the ice storage with different arrangements of the tubes are illustrated in Fig. 10. It should be noted that the number of HTF tubes is kept constant here. The liquid fraction for two different arrangements and two different diameters of the HTF channel, including 12 and $18 \mathrm{~mm}$ versus the time is illustrated in Fig. 11.

Figure 11 shows that firstly, triangular arrangement has better performance than in-line arrangement for both diameter of 12 and $18 \mathrm{~mm}$. It can be seen that before solidification of $75 \%$ of the water, there are no significant differences between these two arrangements for both diameters. Then, the differences appear and it is resulted that triangular arrangement produces more ice than the in-line arrangement for both diameters of the HTF tubes. Also, it should be noticed that according to Fig. 8, case with $\mathrm{d}=12 \mathrm{~mm}$ produces more than case with $\mathrm{d}=18 \mathrm{~mm}$. However, Fig. 11 shows that case with $d=18 \mathrm{~mm}$ and triangular arrangement produces the same amount of ice as the case with $\mathrm{d}=12 \mathrm{~mm}$ and in-line arrangement. On the other hand, by choosing a better arrangement can improve the thermal performance of ice storage.

In order to realize better the ice formation in triangular arrangement of HTF tubes, the liquid fraction contours for two diameter of the tubes $(\mathrm{d}=12$ and $18 \mathrm{~mm})$ and various time are illustrated in Fig. 12. It can be seen that triangular arrangement has positive effect on solidification process. Also, in this arrangement, case with $d=12 \mathrm{~mm}$ produces more ice than case with $d=18 \mathrm{~mm}$. The results show the same output with Figs. 8 and 9.

\subsection{Proposed model for liquid fraction (LF)}

Effect of different parameters of tube diameters, HTF tubes arrangements, and melting time on solidification process of IC storage system were studied by numerical results. In order to formulate these effects, numerical results are analyzed applying ANOVA and multilinear regression by Minitab software [39]. Square root of LF was used to normalize the output for using in ANOVA analysis. $A$ and $B$ in Fig. 13 represents in-line and triangular patterns respectively. Results of summarized in Fig. 13. Results show that melting time $(P$ value $=0.000)$ and tube diameter $(P$ value $=0.000$ ) have significant impacts on $L F$, while HTF tubes arrangements ( $P$ value $=0.048$ ) has no considerable 


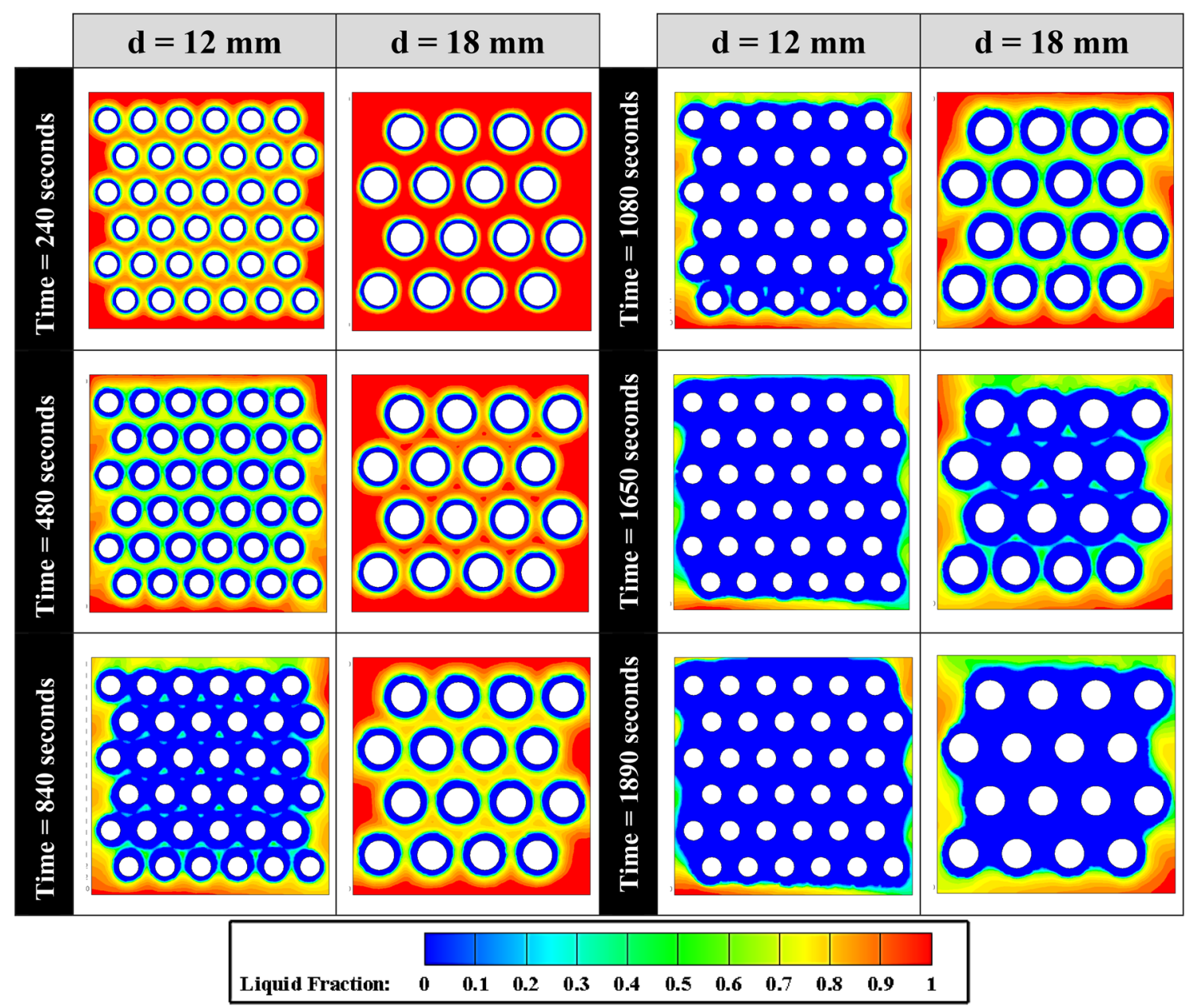

Fig. 12 Contours of liquid fraction (LF) at six different times for triangular arrangements and $\mathrm{d}=12$ and $18 \mathrm{~mm}$

effect (Fig. 13a). As tube diameter increases, LF considerably decreases, especially for $\mathrm{d} \leq 18 \mathrm{~mm}$ (Fig. 13b). Moreover, ANOVA analysis indicate that variation of LF is higher for Triangular arrangement as compared to In-line arrangement (Fig. 13c).

Based on the multilinear regression analysis, Eq. (11) was obtained to formulate LF as a function of tube diameter and melting time, as follows:
$\sqrt{L F}=0.4376+0.021 d-0.0114 t$

where $L F$ is liquid fraction, $d$ is tube diameter, and $t$ is melting time. Based on ANOVA results (Fig. 13), effect of pattern type is ignored in Eq. (11). Correlation of $R^{2}=0.87$ was reported by Minitab software [39]. Performance of Eq. (11) is shown in Fig. 14. An accepted correlation exists between the numerical results and predicted values. 


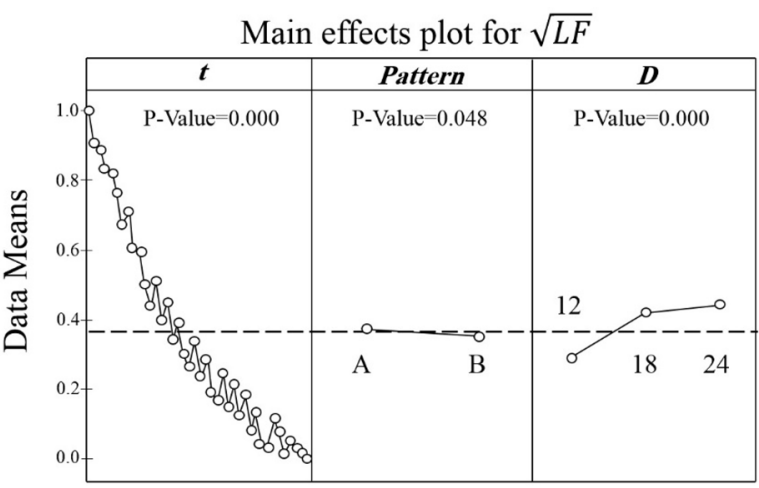

(a)

Interval plot of $\sqrt{L F}$

$95 \% \mathrm{Cl}$ for the mean

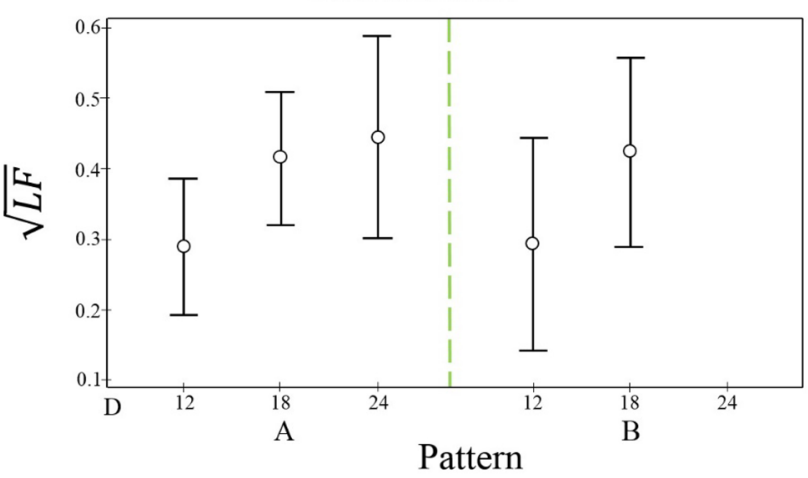

(b)

Interval plot of $\sqrt{L F}$ vs Pattern $95 \% \mathrm{Cl}$ for the mean

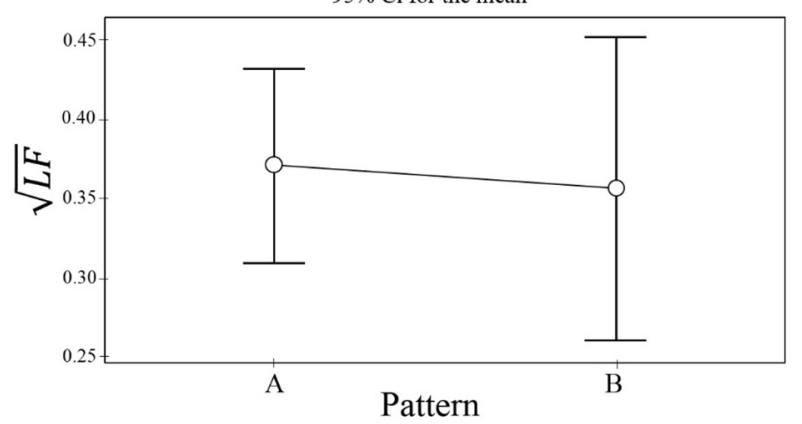

(c)

Fig. 13 ANOVA results: a significancy of parameter; $\mathbf{b}$ interval plot for $D$ and pattern; $c$ interval plot of pattern ( $A$ and $B$ represents inline and triangular patterns respectively)

\section{Conclusion}

In this paper, the water freezing in an ice storage system (ice-on-coil type) is evaluated by performing numerical simulations. The considered computational domain is a two dimensional square shell and different number of heat transfer fluid tubes. Tw-dimensional transient numerical simulations are performed by a commercial CFD

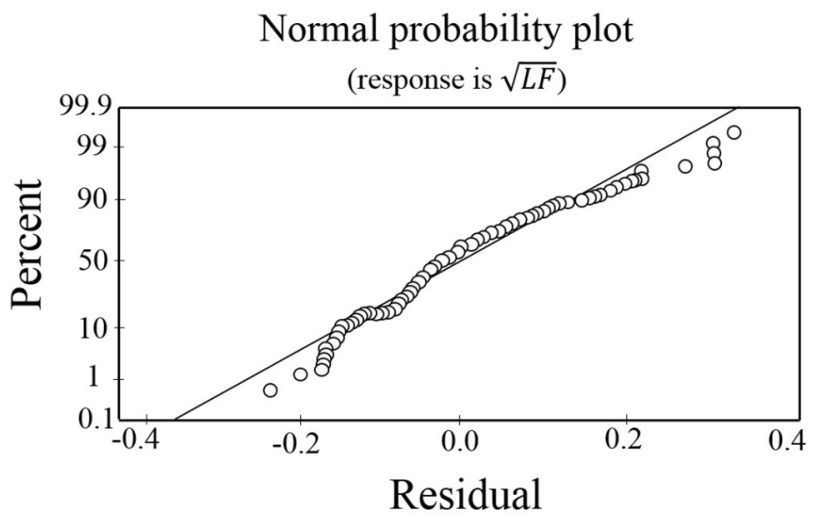

(a)

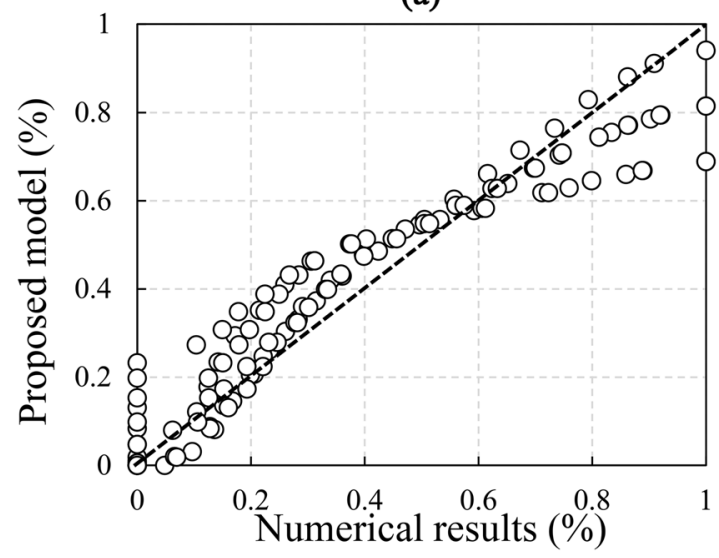

(b)

Fig. 14 Performance of Eq. (11): a normal probability plot by Minitab [39]; b predicted versus numerical results

code, ANSYS FLUENT 18.2. The effects of the diameter (or number) of the Heat transfer fluid tubes and the arrangement of the tubes on solidification process are evaluated. Three different diameters of tubes, including 12,18 , and $24 \mathrm{~mm}$ are considered. Also, two different arrangements of tubes, including in-line and triangular arrangements are studied. Results indicate that as the diameter of the tubes decreases or the number of tubes increase in constant mass flowrate of heat transfer fluid, ice formation rises. Also, triangular arrangement as a staggered arrangement results in high ice formation in comparison with the in-line arrangement. As a result, an accepted correlation for liquid fraction (LF) is presented between the numerical results and predicted values as a function of tube diameter and melting time.

\section{Compliance with ethical standards}

Conflict of interest The authors declare that they have no conflict of interest. 


\section{References}

1. Pocketbook S (2016) EU transport in figures. Publications Office of the European Union, Luxembourg

2. Knebel DE (1990) Off-peak cooling with thermal storage. ASHRAE J 32(4):40-44

3. Basecq V, Michaux G, Inard C, Blondeau P (2013) Short-term storage systems of thermal energy for buildings: a review. Adv Build Energy Res 7(1):66-119

4. Thumann A (1988) Optimizing HVAC systems. Fairmont Press, Lilburn

5. Yi W, Dong W (2015) Modeling and simulation of discharging characteristics of external melt ice-on coil storage system. Int J Smart Home 9(2):179-192

6. Korti AIN (2016) Numerical heat flux simulations on double-pass solar collector with PCM spheres media. Int J Air-Cond Refrig 24(02):1650010

7. Rahdar MH, Emamzadeh A, Ataei A (2016) A comparative study on PCM and ice thermal energy storage tank for air-conditioning systems in office buildings. Appl Therm Eng 96:391-399

8. Kang Z, Wang R, Zhou X, Feng G (2017) Research status of icestorage air-conditioning system. Procedia Eng 205:1741-1747

9. Jannesari H, Abdollahi N (2017) Experimental and numerical study of thin ring and annular fin effects on improving the ice formation in ice-on-coil thermal storage systems. Appl Energy 189:369-384

10. Shih Y-C, Chou H (2005) Numerical study of solidification around staggered cylinders in a fixed space. Numer Heat Trans Part A Appl 48(3):239-260

11. Yang T, Sun Q, Wennersten R (2018) The impact of refrigerant inlet temperature on the ice storage process in an ice-on-coil storage plate. Energy Procedia 145:82-87

12. Erek A, Akif Ezan M (2007) Experimental and numerical study on charging processes of an ice-on-coil thermal energy storage system. Int J Energy Res 31(2):158-176

13. Ezan MA, Erek A, Dincer I (2011) Energy and exergy analyses of an ice-on-coil thermal energy storage system. Energy 36(11):6375-6386

14. Sang WH, Lee YT, Chung JD, Kim ST, Kim T, Oh C-H, Lee K-H (2016) Efficient numerical approach for simulating a full scale vertical ice-on-coil type latent thermal storage tank. Int Commun Heat Mass Transf 78:29-38

15. Mousavi Ajarostaghi SS, Poncet S, Sedighi K, Delavar MA (2019) Numerical modeling of the melting process in a shell and coil tube ice storage system for air-conditioning application. Appl Sci 9(13):2726

16. Pakzad K, Mousavi Ajarostaghi SS, Sedighi K (2019) Numerical simulation of solidification process in an ice-on-coil ice storage system with serpentine tubes. SN Appl Sci 1:1258. https ://doi.org/10.1007/s42452-019-1316-4

17. Afsharpanah F, Mousavi Ajarostaghi SS, Sedighi K (2019) The influence of geometrical parameters on the ice formation enhancement in a shell and double coil ice storage system. SN Appl Sci 1:1264. https://doi.org/10.1007/s42452-019-1317-3

18. Zheng ZH, Ji C, Wang WX (2011) Numerical simulation of internal melt ice-on-coil thermal storage system. Energy Procedia 12:1042-1048

19. Xie J, Yuan C (2014) Numerical study of thin layer ring on improving the ice formation of building thermal storage system. Appl Therm Eng 69:46-54

20. Xie J, Yuan C (2016) Parametric study of ice thermal storage system with thin layer ring by Taguchi method. Appl Therm Eng 98:246-255
21. Ismail KA, Sousa LM, Lino FA (2015) Solidification of PCM around curved tubes including natural convection effects. Int J Energy Eng 5:57-74

22. Sheikholeslami M, Rokni HB (2017) Melting heat transfer influence on nanofluid flow inside a cavity in existence of magnetic field. Int J Heat Mass Transf 114:517-526

23. Sheikholeslami M (2018) Finite element method for PCM solidification in existence of $\mathrm{CuO}$ nanoparticles. J Mol Liq 265:347-355

24. Sheikholeslami M (2018) Numerical simulation for solidification in a LHTESS by means of nano-enhanced PCM. J Taiwan Inst Chem Eng 86:25-41

25. Sheikholeslami M (2018) Solidification of NEPCM under the effect of magnetic field in a porous thermal energy storage enclosure using $\mathrm{CuO}$ nanoparticles. J Mol Liq 263:303-315

26. Sheikholeslami M (2018) Numerical modeling of nano enhanced PCM solidification in an enclosure with metallic fin. J Mol Liq 259:424-438

27. Gawande TK, Ingole DS (2019) Comparative study of heat storage and transfer system for solar cooking. SN Appl Sci. https ://doi.org/10.1007/s42452-019-1753-0

28. Pradhan R, Ramaswamy AP (2019) Encapsulation of paraffin wax by rigid cross-linked poly (styrene divinylbenzene-acrylic acid) and its thermal characterization. SN Appl Sci 1(8):859

29. Sheikholeslami M, Ghasemi A (2018) Solidification heat transfer of nanofluid in existence of thermal radiation by means of FEM. Int J Heat Mass Transf 123:418-431

30. Sheikholeslami M, Li Z, Shafee A (2018) Lorentz forces effect on NEPCM heat transfer during solidification in a porous energy storage system. Int J Heat Mass Transf 127:665-674

31. Sheikholeslami M, Ghasemi A, Li Z, Shafee A, Saleem S (2018) Influence of $\mathrm{CuO}$ nanoparticles on heat transfer behavior of PCM in solidification process considering radiative source term. Int J Heat Mass Transf 126:1252-1264

32. Sheikholeslami M, Haq RU, Shafee A, Li Z (2019) Heat transfer behavior of nanoparticle enhanced PCM solidification through an enclosure with $\mathrm{V}$ shaped fins. Int J Heat Mass Transf 130:1322-1342

33. Faghri A, Zhang Y (2006) Transport phenomena in multiphase systems. Elsevier, New York

34. Bejan A (2013) Convection heat transfer. Wiley, Hoboken

35. Mousavi Ajarostaghi SS, Delavar MA, Dolati A (2017) Numerical investigation of melting process in horizontal shell-andtube phase change material storage considering different HTF channel geometries. Heat Transf Res 48:1515-1529

36. Voller VR, Prakash C (1987) A fixed grid numerical modelling methodology for convection-diffusion mushy region phasechange problems. Int J Heat Mass Transf 30(8):1709-1719

37. Michalek T, Kowaleski TA (2003) Simulations of the water freezing process-numerical benchmarks. Task Q 7(3):389-408

38. Sasaguchi K, Kusano K, Viskanta R (1997) A numerical analysis of solid-liquid phase change heat transfer around a single and two horizontal, vertically spaced cylinders in a rectangular cavity. Int J Heat Mass Transf 40(6):1343-1354

39. Minitab I (2014) MINITAB release 17: statistical software for windows. Minitab Inc, State College

Publisher's Note Springer Nature remains neutral with regard to jurisdictional claims in published maps and institutional affiliations. 